\title{
Estudo sobre o correlacionamento do fenômeno das bolhas e sinais elétricos na soldagem subaquática molhada com eletrodos revestidos
}

\section{(Correlating study of bubble phenomenon and electrical signals in underwater wet welding with covered electrodes)}

Frederico de Rosa Oliveira ${ }^{1}$, William Rodrigues Soares ${ }^{l}$, Alexandre Queiroz Bracarense ${ }^{1}$, ${ }^{1}$ Universidade Federal de Minas Gerais, Departamento de Engenharia Mecânica/Laboratório de Robótica, Soldagem e Simulação, Belo Horizonte, Minas Gerais,Brasil, fredoliveira13@yahoo.com.br,william.wrsoares@yahoo.com.br,queiroz@demec.ufmg.br

\section{Resumo}

O fenômeno das bolhas no processo de soldagem subaquática molhada é de vital influência na qualidade final das soldas. O bom entendimento da formação e colapso das bolhas juntamente com o conhecimento do comportamento dos parâmetros de soldagem no decorrer do processo podem proporcionar melhorias nas práticas utilizadas na soldagem subaquática e, consequentemente, melhorias na qualidade final da solda. Para entender e tentar correlacionar o fenômeno de crescimento, destacamento e frequência das bolhas com os sinais elétricos ao longo do processo de soldagem, este trabalho foi desenvolvido. Foram feitos cordões sobre chapa a 0,50 $\mathrm{m}$ de profundidade com três tipos de eletrodos revestidos comerciais, E6013, E7018 e E7024. Para visualização da formação, destacamento e contagem das bolhas foi realizada a filmagem em alta velocidade do processo, juntamente com a aquisição dos sinais elétricos do mesmo. Pôde-se então tentar correlacionar a frequência das bolhas com variações dos sinais elétricos observados durante o process. Observou-se nos dados de corrente que o número médio de variações abaixo de 5\% da corrente média assemelha-se com o a taxa média de destacamento das bolhas. Assim concluiu-se a possibilidade de haver uma relação entre o destacamento das bolhas com determinada variação na corrente.

Palavras-chave: soldagem subaquática molhada, filmagem em alta velocidade, eletrodo revestido, frequência das bolhas e sinais elétricos.

\begin{abstract}
The bubble phenomenon in underwater wet welding is very important in the weld's final quality. A good understanding of the formation and collapse of the bubbles with the knowledge of the welding parameters behavior along the process can improve the practices used in the underwater welding and, consequently, improve the final weld quality. To understand and try to correlate the phenomenon of growth, detachment and frequency of the bubbles with the electrical signals along the welding process this work was done. Three commercial covered electrodes, E6013, E7024 e E7018 were used to made beds on plate in a depth of 0,50 m. To visualize the formation, detachment and counting of the bubbles a high speed camera was used to record the process, together with electrical signals acquisition. So it was possible try to correlate the bubble frequency with the electrical signals observed along the process. That was observed in the currents data that the average number of variations under $5 \%$ of the average current is similar with the average rate of bubbles detachment. Therefore was concluded the possible relationship of the bubble detachment with a determined variation in the current.
\end{abstract}

Key-words: Underwater wet welding, high speed camera, covered electrodes, bubble frequency, electrical signals.

\section{Introdução}

A soldagem subaquática molhada com eletrodo revestido tem sua aplicação principal voltada para o reparo e manutenção de estruturas submersas sendo bastante utilizado na indústria naval e de exploração de petróleo e gás. Esta técnica tem se mostrado bastante versátil além de apresentar baixo custo e produzir soldas com bons níveis de confiabilidade. No entanto

Recebido em 10/07/2012. Texto final em 27/02/2013. deve-se estar atento a procedimentos especiais de soldagem e na utilização de eletrodos especialmente desenvolvidos para este fim. Mesmo produzindo soldas com níveis de confiabilidade aceitáveis e a um custo razoável, alguns fenômenos que influenciam diretamente no resultado da solda subaquática são pouco entendidos.

Um dos principais problemas inerentes ao processo de soldagem subaquática é o seu rápido resfriamento determinado pela água circundante. A elevada velocidade de resfriamento resultante da ação refrigerante da água durante a soldagem impõe algumas características microestruturais ao metal de solda e à zona termicamente afetada (ZTA). São geradas na ZTA microestruturas de elevada dureza que apresentam 
baixa tenacidade e estabelecem variações abruptas de dureza entre metal de solda e ZTA, diminuindo a ductilidade e, consequentemente, a capacidade de deformação da solda [1].

Quando comparada a outros óxidos e ingredientes presentes no revestimento do eletrodo, a água é termodinamicamente instável e se decompõe facilmente em contato com o arco elétrico produzindo hidrogênio e oxigênio. Estes átomos em conjunto com a queima do revestimento do eletrodo formam bolhas ao redor do arco elétrico, protegendo-o. Estas crescem até atingir um volume crítico, depois do qual o equilíbrio de forças hidrodinâmicas é quebrado. Quando as forças de empuxo dominam, as bolhas se destacam da região do arco elétrico movendo-se em direção à superfície onde colapsam [2]. No momento em que a bolha torna-se instável e se destaca do arco elétrico, uma nova bolha forma-se dando continuidade ao ciclo. $\mathrm{O}$ arco elétrico, assim, é sempre protegido pela bolha durante a soldagem subaquática [3].

O fenômeno das bolhas no processo de soldagem subaquática pode estar intimamente relacionado com a forma de resfriamento inerente ao processo. Desta forma o bom entendimento deste fenômeno pode vir a propiciar soldas de melhor qualidade.

Segundo Pope, Medeiros e Liu [4], o processo de resfriamento da soldagem molhada pode ser dividido em dois regimes: resfriamento lento em altas temperaturas (enquanto está sob a proteção da bolha de gás) e resfriamento rápido em temperaturas mais baixas (após o destacamento desta bolha do arco elétrico). O tempo em que acontece o resfriamento lento é muito curto, uma vez que, ao atingir o volume crítico, a bolha se destaca e se move em direção à superfície levando a maior parte do calor e expondo imediatamente o metal parcialmente resfriado à água. A dinâmica das bolhas e a exposição do metal de solda à água são responsáveis pelas altas taxas de resfriamento observadas na soldagem molhada [1].

Enquanto o metal depositado encontra-se dentro da bolha de gás, a perda de calor ocorre de forma semelhante àquela na soldagem atmosférica. No entanto, à medida que o arco avança, o metal de solda passa a ficar em contato direto com o meio aquoso, fazendo com que a perda de calor passe a ser predominantemente por convecção. A elevada quantidade de calor que passa a ser dissipada por convecção altera o formato da poça de fusão fazendo com que esta adquira a forma de gota alongada, aumentando, portanto, a sua susceptibilidade à fissuração a quente. As tensões residuais originadas no ciclo térmico de soldagem são função do grau de restrição oferecido pela junta soldada, sendo a magnitude dessas tensões crescente com o aumento do resfriamento da junta soldada [5].

As características do ambiente no qual o arco elétrico se forma (rico em átomos de hidrogênio e oxigênio, vapor de metal e gases gerados da queima do revestimento) levam a estabilidade do arco e o processo de transferência serem diretamente influenciados pela dinâmica de formação e destacamento das bolhas. Se durante a soldagem as bolhas se mantiverem envolvendo o arco, o processo de transferência tende a se manter estável. Entretanto, se ocorrer o desprendimento das bolhas, o arco extingue e cria uma situação de instabilidade no processo de transferência. A ocorrência do desprendimento das bolhas pode se dar, tanto durante o período de arco, quanto em períodos de extinção do arco, como por exemplo, durante um curto circuito [6].

Este trabalho tem o intuito de tentar correlacionar os fenômenos das bolhas com os sinais elétricos e estes às formas de solidificação do metal de solda através da análise macroscópica dos cordões de solda. Para isto foi realizada a filmagem em alta velocidade e a aquisição dos sinais de corrente e tensão durante a soldagem com três tipos diferentes de eletrodos revestidos comerciais, E6013, E7024 e E7018.

\section{Materiais e Métodos}

Os cordões foram feitos em chapas de aço ASTM A-36 com $8,0 \mathrm{~mm}$ de espessura utilizando-se os eletrodos comerciais E6013, E7024 e E7018, todos com 3,25 mm de diâmetro de alma. As soldas foram realizadas em um aquário a $0,5 \mathrm{~m}$ de profundidade Figura 1. As velocidades de soldagem médias para cada eletrodo foram de $0,41 \mathrm{~cm} / \mathrm{s}$ para o E6013, $0,29 \mathrm{~cm} / \mathrm{s}$ para o E7024 e $0,25 \mathrm{~cm} / \mathrm{s}$ para o E7018.

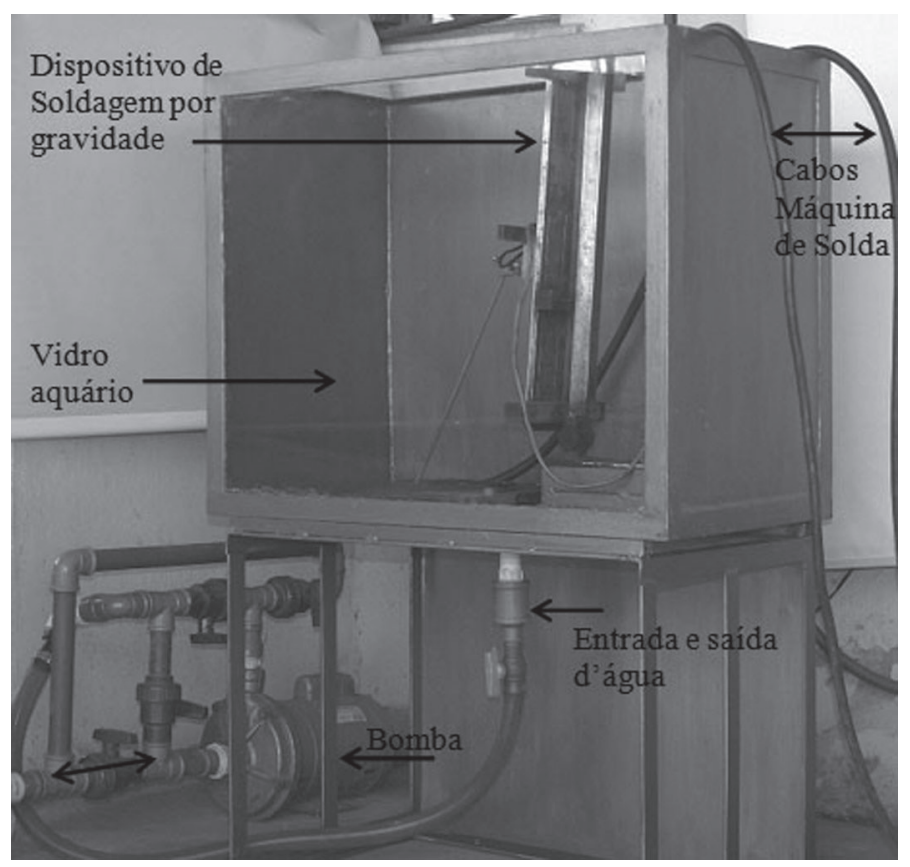

Figura 1 - Aquário de soldagem

As soldas foram realizadas com o auxílio de um dispositivo mecanizado por gravidade para soldagem com eletrodos revestidos, Figura 2. Os valores de corrente e o ângulo de ataque foram selecionados baseados em trabalhos e experimentos prévios a este $[5,7,8]$. Utilizou-se para a soldagem uma fonte de corrente constante, desta forma estabeleceu-se uma corrente e ângulo de ataque $(\theta)$ fixos para os três tipos de eletrodos utilizados. Utilizou-se uma corrente de $160 \mathrm{~A}$ e um ângulo de ataque de $60^{\circ}$.

Para a filmagem em alta velocidade foi utilizada uma câmera com capacidade para gerar e armazenar uma sequência de imagens de vídeo de um evento a uma taxa de 60 a 8.000 quadros por segundo, Figura 3. 


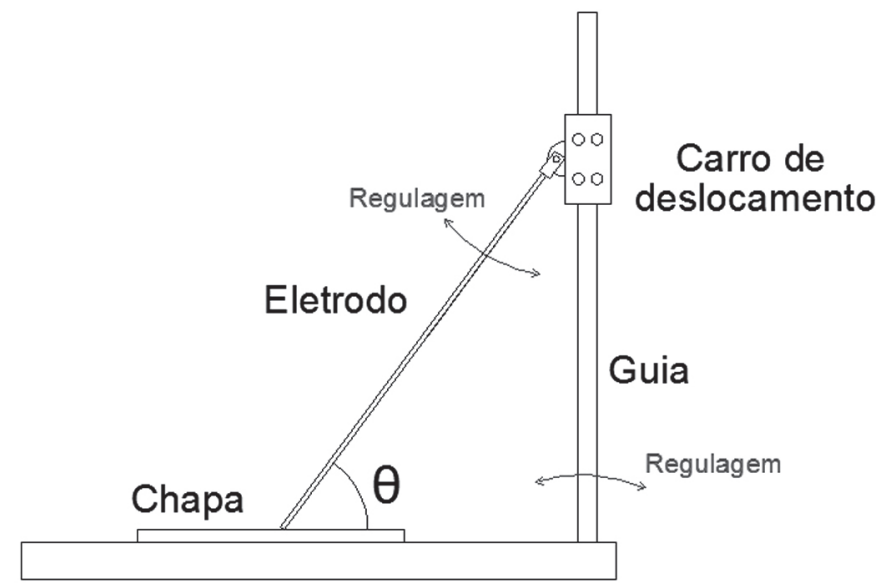

Figura 2 - Esquema do dispositivo de soldagem

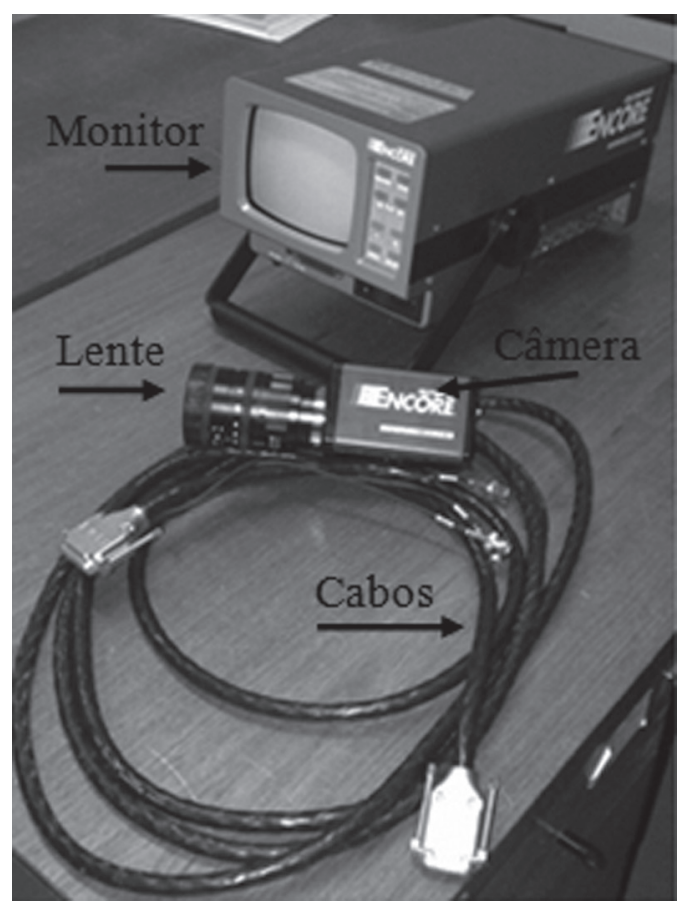

Figura 3 - Câmera Olympus ENCORE MAC-8000S

Para prever o fenômeno das bolhas matematicamente, Tsai e Masubuchi [1] desenvolveram um modelo idealizado para o crescimento da bolha. Este se baseou na formação da bolha a partir de um orifício de uma placa, devido à semelhança desta com o crescimento da bolha na soldagem subaquática. Como resultado, os autores chegaram a uma taxa de descolamento de 15 bolhas/segundo para o eletrodo E6013 e 14 bolhas/segundo para o eletrodo E7014. Neste mesmo trabalho os autores também fizeram a análise da formação das bolhas através da filmagem em alta velocidade da soldagem, chegando a uma taxa de colapso de 13 bolhas/segundo para ambos os eletrodos, valores bem próximos aos calculados pelo modelo matemático.

Baseados no trabalho de Tsai e Masubuchi [1] utilizou-se na para a filmagem neste trabalho uma taxa de 250 quadros/ segundo, taxa que pode ser considerada superior à necessária para se filmar o crescimento, destacamento e colapso das bolhas.
De acordo com as especificações da câmera, com uma taxa de 250 quadros/segundo pode-se realizar a filmagem de até 8,2 segundos.

A Figura 4 mostra a foto da montagem do aparato para realização do processo de soldagem dentro do tanque. Para se obter uma referência fixa ao longo do cordão de solda que poderia ser visualizada nos vídeos, em cada chapa de aço foi feita uma marcação do ponto exato onde se faria a abertura do arco elétrico. Posicionou-se então uma régua com sua origem neste ponto, longitudinalmente ao cordão de solda que seria realizado, Figura 5. Desta forma conseguiu-se obter nos vídeos uma escala no corpo de prova e localizar nos vídeos o início e o fim das gravações, além da região aproximada onde ocorreram os colapsos das bolhas ao longo do cordão.

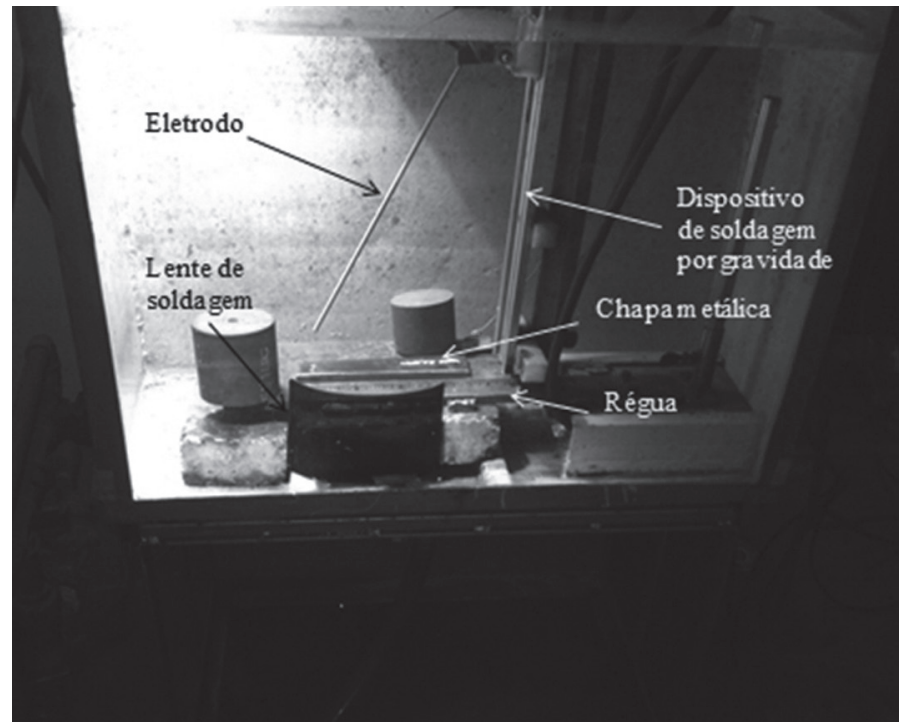

Figura 4 - Foto da montagem dentro do tanque de soldagem

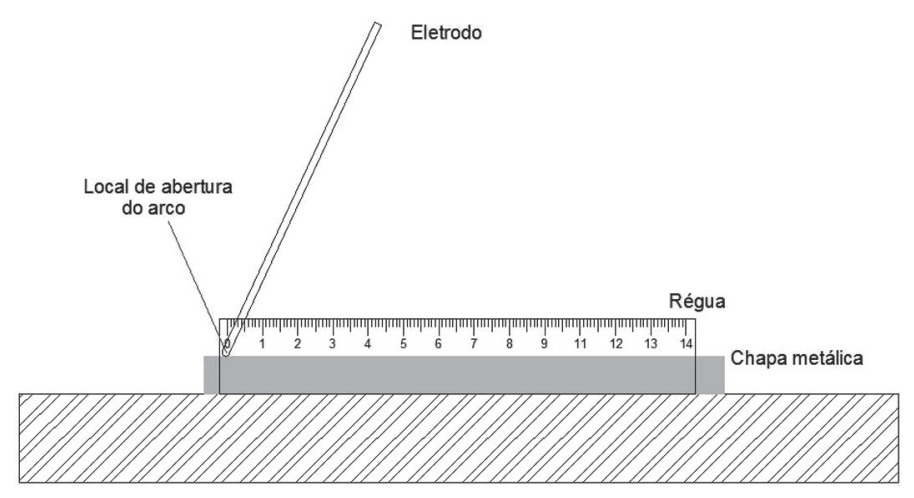

Figura 5 - Esquema usado para obter referência do cordão de solda nos vídeos

Como citado anteriormente, a câmera possui uma limitação de tempo para realização da filmagem de acordo com a taxa de quadros/segundo selecionada para gravação. Esta limitação de tempo em conjunto com a distância ideal para se obter o melhor foco e uma imagem nítida nos vídeos restringiu a área de filmagem da câmera, impossibilitando realizar a gravação de todo o cordão de solda.

Para excluir das análises os efeitos de abertura e extinção 
Tabela 1 - Corpos de Prova

\begin{tabular}{|c|c|c|c|c|c|c|c|c|c|c|c|c|c|c|}
\hline \multicolumn{5}{|c|}{ Corpos de Prova Eletrodo E6013 } & \multicolumn{5}{|c|}{ Corpos de Prova Eletrodo E7024 } & \multicolumn{5}{|c|}{ Corpos de Prova Eletrodo E7018 } \\
\hline $1 \mathrm{~A}$ & $2 \mathrm{~A}$ & $3 \mathrm{~A}$ & $4 \mathrm{~A}$ & $5 \mathrm{~A}$ & $1 \mathrm{~B}$ & $3 \mathrm{~B}$ & $4 \mathrm{~B}$ & $5 B$ & $6 \mathrm{~B}$ & $1 \mathrm{C}$ & $2 \mathrm{C}$ & $3 \mathrm{C}$ & $4 \mathrm{C}$ & $5 \mathrm{C}$ \\
\hline
\end{tabular}

do arco elétrico, que não é o objetivo principal deste trabalho, a câmera foi posicionada de forma a capturar as imagens distantes de 2 a $3 \mathrm{~cm}$ ao longo de onde seria feita a abertura do arco elétrico. Desta forma, o arco elétrico era aberto, e só após entrar no campo de visão da câmera se iniciava a gravação. $\mathrm{O}$ arco elétrico só era extinto após sair do campo de visão da câmera.

Diferente da filmagem, a aquisição de dados se iniciou com a abertura do arco elétrico. Desta forma a imagem gravada não estava sincronizada com os sinais elétricos. No intuito de sincronizar estes, a associação das imagens gravadas com os sinais aquisitados pelo sistema foi feita em três etapas: inicialmente definiu-se a velocidade média de soldagem, na sequência determinou-se a distância do início da filmagem à origem da abertura do arco (através da régua posicionada a frente da chapa de metal) e por fim, através destas determinou-se o tempo do início de abertura do arco até o início da filmagem. Apesar deste método não ser muito preciso devido as variáveis de trabalho estarem na escala de milésimos de segundo e décimos de milímetro (tanto para a filmagem quanto para a aquisição de dados), ele se fez necessário devido a limitação de tempo para as filmagens segundo as especificações da câmera.

Devido às limitações experimentais citadas anteriormente não foi possível correlacionar com exatidão os fenômenos observados nos vídeos, os sinais de aquisição do processo e os corpos de prova de cada cordão. No entanto procurou-se realizar uma análise bem criteriosa tentando-se coincidir ao máximo estes três parâmetros

Apesar da capacidade da câmera realizar a filmagens de até 8,2 segundos determinou-se a análise para apenas 8,0 segundos de todos os parâmetros, dos dados de aquisição, dos vídeos e das áreas dos corpos de prova.

Foram analisados 5 cordões de solda para cada tipo eletrodo. Cada cordão originou um corpo de prova conforme Tabela 1.

Os sinais elétricos foram importados e trabalhados com o auxílio de uma planilha eletrônica. A taxa de aquisição foi definida em $1.000 \mathrm{~Hz}$, assim para a análise de 8,0 segundos obteve-se 8.000 sinais para corrente e para tensão. O índice de estabilidade do arco foi definido por Madatov apud Bracarense [8]. Para se calcular os valores de S, utilizou-se o seguinte método: a cada intervalo de 0,01 segundos ( 10 pontos aquisitados pelo sistema) dividiu-se a corrente máxima (Imax) pela corrente mínima (Imin) encontrada, obtendo-se assim 800 valores de S para cada cordão. Com estes 800 valores calculou-se o valor médio de $\mathrm{S}\left(\mathrm{S}_{\mathrm{m}}\right)$ para todo o cordão de solda.

Apesar de ter-se utilizada uma fonte de corrente contínua, optou-se pela análise da corrente ao invés da tensão pelo fato desta se comportar de maneira bastante aleatória. Além disto, bruscas variações geradas pelo destacamento das bolhas causariam alterações no arco elétrico que seriam melhor caracterizadas e visualizadas por variações na corrente.

As imagens gravadas foram analisadas segundo a formação, crescimento e descolamento das bolhas. Foram contadas o número de bolhas que se formavam a cada segundo e determinouse a taxa média de destacamento das bolhas.

Os corpos de prova foram cortados longitudinalmente para realização de sua análise metalográfica.

\section{Resultados e Discussão}

\subsection{Sinais elétricos}

A Figura 6 mostra o gráfico com os valores de estabilidade do arco para cada corpo de prova.

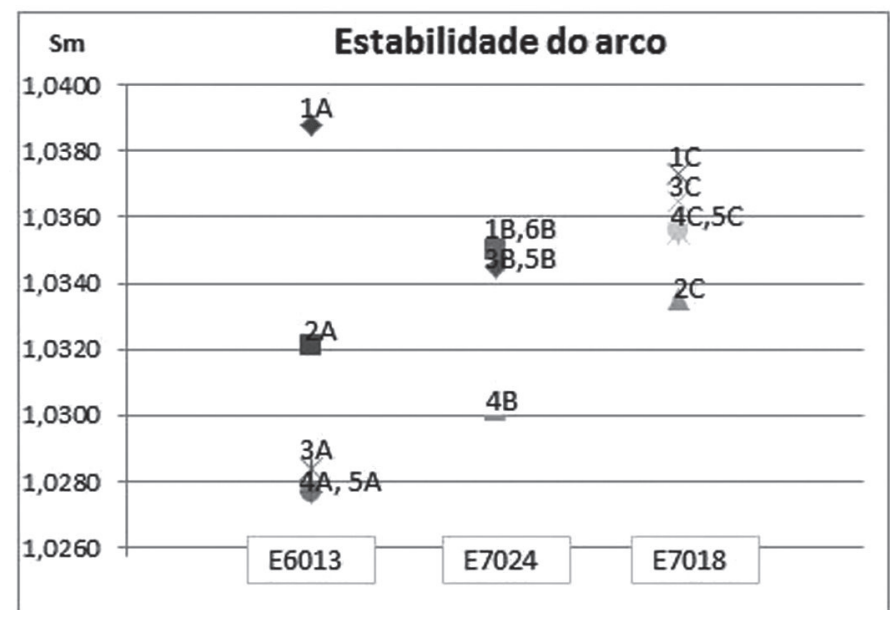

Figura 6 - Valores para estabilidade do arco

Em uma análise geral pode-se ver que não há variações muito grandes nos valores de $\mathrm{S}_{\mathrm{m}}$ para todos os eletrodos. No entanto, na média dos valores, os cordões feitos com eletrodo E6013 geraram arcos mais estáveis (menores valores de $\mathrm{S}_{\mathrm{m}}$ ) se comparados aos realizados com eletrodo E7024, e estes mais estáveis que os realizados com o eletrodo E7018, salvo exceção para os corpos de prova 1A, 4B e $2 \mathrm{C}$ cujos valores de $\mathrm{S}_{\mathrm{m}}$ desviaram significativamente dos valores dos demais corpos de prova soldados com o mesmo tipo de eletrodo.

\subsection{Desvios percentuais em relação à tensão e corrente médias}

Com os valores de tensão e corrente aquisitados durante o processo foram calculados os valores de tensão média $\left(\mathrm{V}_{\mathrm{m}}\right)$ e corrente média $\left(\mathrm{A}_{\mathrm{m}}\right)$. Este cálculo foi realizado no intuito de definir-se em torno de quais valores a tensão e corrente variaram e tentar verificar algum padrão em relação a estas variações. As variações dos sinais de tensão aquisitados em relação à tensão média apresentaram-se bastante significativos ao longo do processo de soldagem, chegando até a 50\%. Já para a corrente, 
as variações dos sinais aquisitados foram mais brandas, até $10 \%$ em relação a sua corrente média. Visto isto, definiramse então escalas de variação da tensão e corrente em relação aos seus valores médios, $0, \pm 5, \pm 10, \pm 15, \pm 20, \pm 25, \pm 30, \pm 35$ $\pm 40, \pm 45$ e $\pm 50 \%$ para a tensão e $0,+1,+2, \pm 3, \pm 4, \pm 5, \pm 6$, $\pm 7, \pm 8, \pm 9$ e $\pm 10 \%$ para corrente. Em seguida computou-se o número de eventos por segundo em que os sinais elétricos aquisitados superavam estes valores pré-estabelecidos ao longo do processo de soldagem. Gráficos foram criados para analisar este comportamento. Valores acima e abaixo de $0 \%$ da tensão e corrente média representam o número de eventos acima e abaixo destes valores médios.

Nas Figuras 7, 8 e 9 são mostrados o comportamento do percentual de eventos por segundo da tensão conforme se afastam de $\mathrm{V}_{\mathrm{m}}$ para cada eletrodo.

\section{E6013}

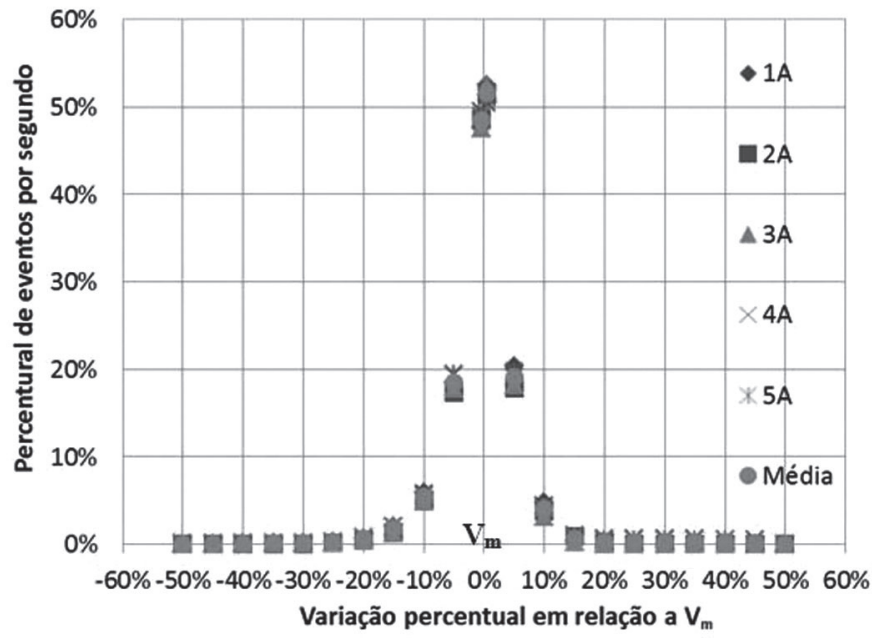

Figura 7 - Gráfico da distribuição de eventos/s em relação a desvios percentuais da $\mathrm{V}_{\mathrm{m}}$ - eletrodo E6013

E7024

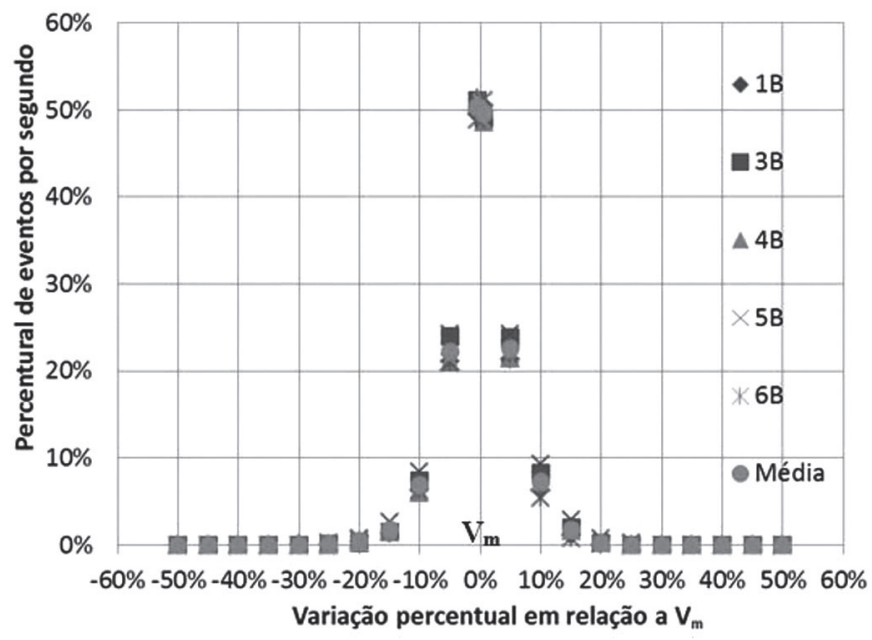

Figura 8 - Gráfico da distribuição de eventos/s em relação a desvios percentuais da $\mathrm{V}_{\mathrm{m}}$ - eletrodo E7024
E7018

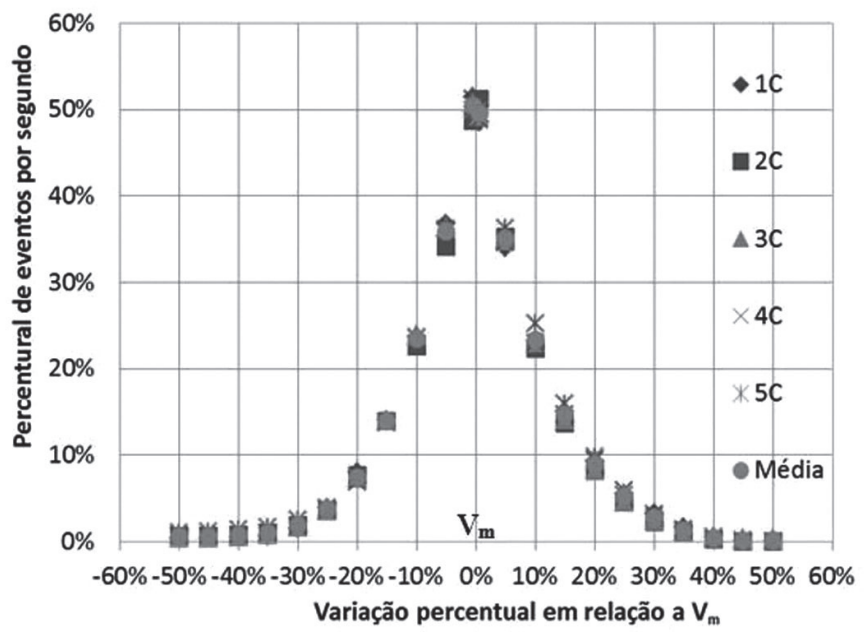

Figura 9 - Gráfico da distribuição de eventos/s em relação a desvios percentuais da $\mathrm{V}_{\mathrm{m}}$ - eletrodo E7018

Analisando os desvios percentuais nota-se que o comportamento dos eletrodos E6013 e E7024 são semelhantes. Estes apresentam reduções bruscas iniciais no percentual de eventos conforme se distanciam da $\mathrm{V}_{\mathrm{m}}$, por exemplo, de percentuais em torno de $50 \%$ para próximos a $20 \%$ e depois abaixo de $10 \%$, para valores tanto maiores como menores que a $\mathrm{V}_{\mathrm{m}}$. $\mathrm{O}$ eletrodo $\mathrm{E} 7018$, porém, apresenta uma redução menos acentuada destes percentuais, em torno de 50\%, 35\%, 23\% e $15 \%$ conforme se afastam de $\mathrm{V}_{\mathrm{m}}$. No entanto, para todos os eletrodos observa-se uma distribuição semelhante para o mesmo percentual de desvio acima e abaixo da $\mathrm{V}_{\mathrm{m}}$, por exemplo, no eletrodo E7018 com um desvio de 10\% acima da $\mathrm{V}_{\mathrm{m}}$ tem-se aproximadamente $23 \%$ dos eventos e para $10 \%$ abaixo de $\mathrm{V}_{\mathrm{m}}$ tem-se também valores próximos a $23 \%$ dos eventos.

As figuras 10, 11 e 12 apresentam os desvios percentuais dos eventos por segundo em relação a $\mathrm{A}_{\mathrm{m}}$ para cada corpo de prova de cada eletrodo.

\section{E6013}

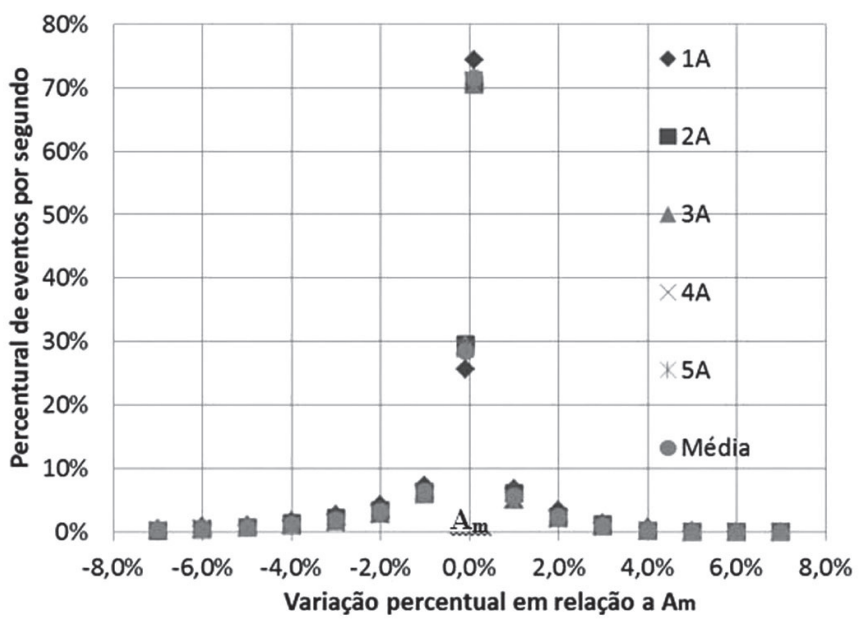

Figura 10 - Gráfico da distribuição de eventos/s em relação a desvios percentuais da $\mathrm{A}_{\mathrm{m}}$ - eletrodo E6013 
E7024

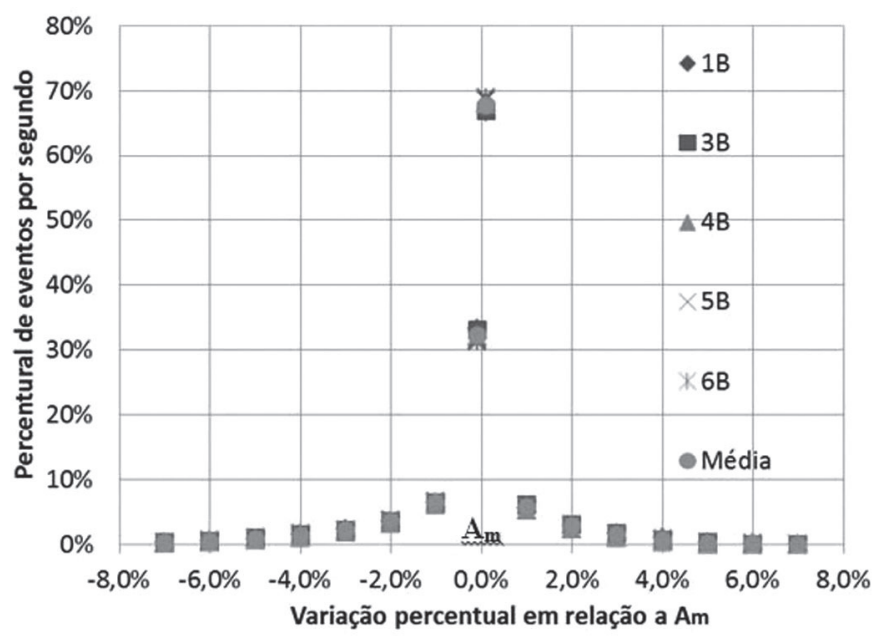

Figura 11 - Gráfico da distribuição de eventos/s em relação a desvios percentuais da $\mathrm{A}_{\mathrm{m}}$ - eletrodo E7024

\section{E7018}

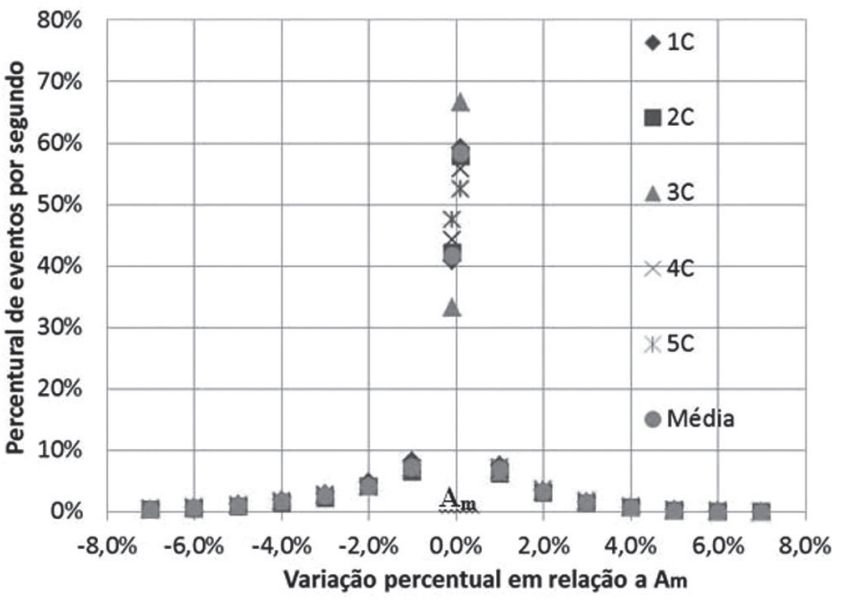

Figura 12 - Gráfico da distribuição de eventos/s em relação a desvios percentuais da $\mathrm{A}_{\mathrm{m}}$ - eletrodo E7018

Inicialmente percebe-se que os desvios percentuais em relação à tensão são maiores que os em relação a corrente devido a utilização de uma fonte de corrente constante. Percebe-se também que há uma maior concentração de eventos acima da $\mathrm{A}_{\mathrm{m}}$, próximos a $70 \%$ nos eletrodos E6013 e E7024 e próximos a $60 \%$ para o eletrodo E7018. Para todos os eletrodos notase também um comportamento semelhante na redução do percentual de eventos conforme se distancia de $\mathrm{A}_{\mathrm{m}}$ : uma queda brusca inicial seguidas de reduções mais brandas. Por exemplo, na Figura 11, para o eletrodo E7024 tem-se uma queda de 32\% aproximadamente para valores próximos a $6 \%$, seguidas de quedas menos expressivas conforme se afasta da $\mathrm{A}_{\mathrm{m}}$.

\subsection{Análise das filmagens em alta velocidade}

Segundo Pope, Medeiros e Liu [4], o arco elétrico e a poça de fusão estão sempre dentro da bolha de vapor d'água devido a temperatura de vaporização da água ser significativamente menor do que a temperatura de solidificação da solda. Assim, após a abertura do arco elétrico tem-se um processo continuo de formação e colapso de bolhas.

Visualmente, o mecanismo de formação e colapso das bolhas pode ser descrito conforme a seguir. Após o colapso de uma bolha há o início do crescimento de outra bolha ao redor do arco elétrico. Em determinado momento há uma diminuição significativa da intensidade luminosa do arco elétrico. Neste momento é visto a bolha se desprendendo da região do arco. Automaticamente a luminosidade do arco aumenta e inicia-se novamente a formação de uma nova bolha. Na Figura 13 é visto frame por frame este processo de formação e colapso da bolha. Cada frame equivale a 4 milissegundos.

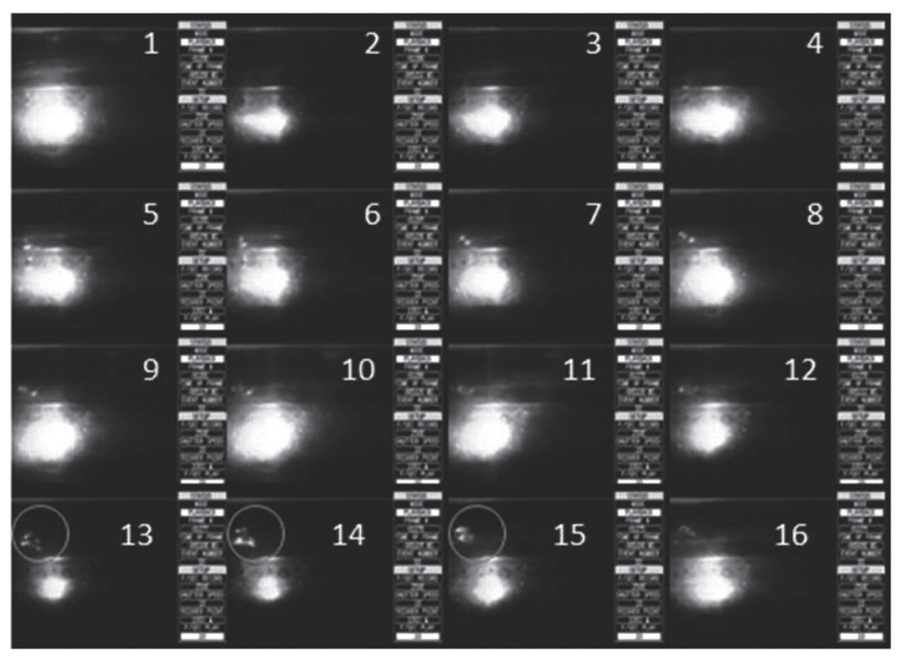

Figura 13 - Formação e destacamento das bolhas

Nos frames 1 a 11 é visto o arco elétrico com sua luminosidade normal, enquanto a bolha está crescendo. No frame 12 já notase uma diminuição desta luminosidade. Nos frames 13, 14 e 15 acontece o destacamento da bolha, que aparece circulada. Após o destacamento a luminosidade volta a aumentar e inicia-se o crescimento de outra bolha.

Conforme já citado anteriormente foram analisados 8,0 segundos do processo de soldagem, com um total de 2.000 frames. A contagem de bolhas foi dividida para cada segundo e realizada para todos os corpos de prova. Os resultados podem ser vistos nas Tabelas 2, 3 e 4 . As células realçadas em cinza identificam um regime turbulento das bolhas nos quais não se conseguiu determinar com precisão o total de bolhas. 
Tabela 2 - Contagem bolhas para o eletrodo E6013

\begin{tabular}{|c|c|c|c|c|c|c|c|c|c|c|}
\cline { 2 - 14 } \multicolumn{1}{c|}{} & \multicolumn{10}{c|}{ Número de bolhas } \\
\hline $\begin{array}{c}\text { Corpo de } \\
\text { Prova }\end{array}$ & $\mathbf{0}$ a 1 seg & $\mathbf{1}$ a 2 seg & $\mathbf{2}$ a 3 seg & $\mathbf{3}$ a 4 seg & $\mathbf{4}$ a 5 seg & $\mathbf{5}$ a 6 seg & $\mathbf{6}$ a 7 seg & 7 a 8 seg & Média & $\begin{array}{c}\text { Desvio } \\
\text { Padrão }\end{array}$ \\
\hline 1A & 8 & 7 & 12 & 11 & 11 & 11 & 9 & 11 & 10 & 1,8 \\
\hline 2A & 10 & 8 & 11 & 8 & 8 & 9 & 9 & 11 & 9 & 1,3 \\
\hline 3A & 9 & 9 & 10 & 10 & 10 & 9 & 12 & 10 & 10 & 1,0 \\
\hline 4A & 10 & 9 & 8 & 11 & 9 & 9 & 9 & 8 & 9 & 1,0 \\
\hline 5A & 9 & 11 & 11 & 10 & 10 & 11 & 11 & 8 & 10 & 1,1 \\
\hline
\end{tabular}

Tabela 3 - Contagem bolhas para o eletrodo E7024

\begin{tabular}{|c|c|c|c|c|c|c|c|c|c|c|}
\cline { 2 - 13 } \multicolumn{1}{c|}{} & \multicolumn{9}{c|}{ Número de bolhas } \\
\hline $\begin{array}{c}\text { Corpo de } \\
\text { Prova }\end{array}$ & $\mathbf{0}$ a 1 seg & $\mathbf{1}$ a 2 seg & $\mathbf{2}$ a 3 seg & $\mathbf{3}$ a 4 seg & $\mathbf{4}$ a 5 seg & $\mathbf{5}$ a 6 seg & $\mathbf{6}$ a 7 seg & 7 a 8 seg & Média & $\begin{array}{c}\text { Desvio } \\
\text { Padrão }\end{array}$ \\
\hline 1B & 7 & 8 & 7 & 7 & 7 & 7 & 8 & 8 & 7 & 0,5 \\
\hline 3B & 8 & 10 & 9 & 11 & 10 & 10 & 10 & 10 & 10 & 0,9 \\
\hline 4B & 5 & 8 & 9 & 8 & 9 & 8 & 6 & 9 & 8 & 1,5 \\
\hline 5B & 9 & 8 & 9 & 11 & 7 & 8 & 8 & 9 & 9 & 1,2 \\
\hline 6B & 11 & 8 & 8 & 9 & 7 & 9 & 8 & 7 & 8 & 1,3 \\
\hline
\end{tabular}

Tabela 4 - Contagem bolhas para o eletrodo E7018

\begin{tabular}{|c|c|c|c|c|c|c|c|c|c|c|}
\cline { 2 - 14 } & \multicolumn{10}{c|}{ Número de bolhas } \\
\hline $\begin{array}{c}\text { Corpo de } \\
\text { Prova }\end{array}$ & $\mathbf{0}$ a 1 seg & $\mathbf{1}$ a 2 seg & $\mathbf{2}$ a 3 seg & $\mathbf{3}$ a 4 seg & $\mathbf{4}$ a 5 seg & $\mathbf{5}$ a 6 seg & $\mathbf{6}$ a 7 seg & 7 a 8 seg & Média & $\begin{array}{c}\text { Desvio } \\
\text { Padrão }\end{array}$ \\
\hline 1C & 11 & 12 & 11 & 11 & 11 & 9 & 11 & 11 & 11 & 0,8 \\
\hline 2C & 11 & 11 & 11 & 11 & 10 & 10 & 11 & 11 & 11 & 0,5 \\
\hline 3C & 12 & 10 & 10 & 9 & 10 & 9 & 11 & 10 & 10 & 1,0 \\
\hline 4C & 9 & 10 & 10 & 11 & 12 & 11 & 12 & 11 & 11 & 1,0 \\
\hline 5C & 10 & 11 & 11 & 10 & 11 & 9 & 11 & 11 & 11 & 0,8 \\
\hline
\end{tabular}

Não se observou um padrão muito rígido de colapso das bolhas. Mesmo para corpos de prova do mesmo eletrodo notamse valores médios diferentes entre eles. Observa-se também que nenhum valor médio encontrado nestes testes foram iguais aos resultados encontrados por Tsai e Masubuchi [1] que descreveu uma taxa de 13 bolhas/segundo, no entanto são bem próximos.

\subsection{Correlacionamento dos sinais elétricos e colapso de bolhas}

Através das tabelas com a contagem dos eventos por segundo que desviavam da tensão e corrente médias pôde-se observar uma semelhança entre a taxa de bolhas por segundo contadas através da filmagem em alta velocidade com o total de eventos por segundo menores que $5 \%$ da $\mathrm{A}_{\mathrm{m}}$, Tabela 5 .

As Figuras 14, 15 e 16 mostram este comparativo graficamente, eventos/segundo $5 \%$ menores que a corrente média $\left(\mathrm{A}_{\mathrm{m}}\right)$ e a taxa de destacamento das bolhas.

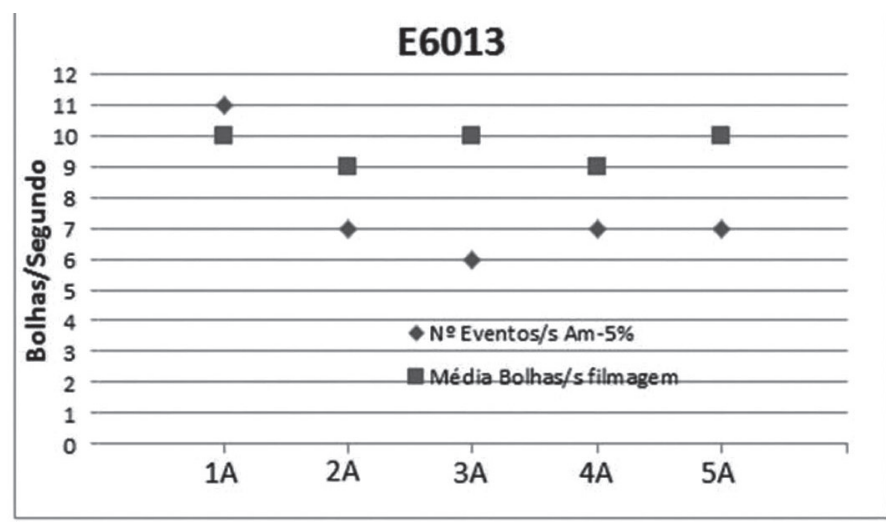

Figura 14 - Comparativo Eventos/s 5\% menores que $\mathrm{A}_{\mathrm{m}}$ e a média bolhas/s registrados com a filmagem - Eletrodo E6013 
Tabela 5 - Total de eventos por segundo menores que $\mathrm{A}_{\mathrm{m}}$ por corpo de prova

\begin{tabular}{|c|c|c|c|c|c|c|c|c|c|c|c|c|c|c|c|}
\hline \multirow{2}{*}{$\begin{array}{c}\text { Variação Corrente } \\
\text { Média }\end{array}$} & \multicolumn{5}{|c|}{ E6013 } & \multicolumn{5}{|c|}{ E7024 } & \multicolumn{5}{|c|}{ E7018 } \\
\hline & $1 \mathrm{~A}$ & $2 \mathrm{~A}$ & $3 \mathrm{~A}$ & $4 \mathrm{~A}$ & $5 \mathrm{~A}$ & $1 \mathrm{~B}$ & $3 \mathrm{~B}$ & $4 \mathrm{~B}$ & $5 \mathrm{~B}$ & $6 \mathrm{~B}$ & $1 \mathrm{C}$ & $2 \mathrm{C}$ & $3 \mathrm{C}$ & $4 \mathrm{C}$ & $5 \mathrm{C}$ \\
\hline$<$ Am & 256 & 295 & 295 & 292 & 289 & 334 & 331 & 321 & 315 & 312 & 409 & 422 & 333 & 442 & 476 \\
\hline Am-1\% & 73 & 61 & 59 & 62 & 62 & 65 & 65 & 61 & 67 & 65 & 83 & 66 & 73 & 66 & 69 \\
\hline Am-2\% & 42 & 34 & 29 & 28 & 29 & 36 & 35 & 33 & 38 & 36 & 48 & 41 & 41 & 40 & 41 \\
\hline Am-3\% & 27 & 21 & 16 & 15 & 15 & 24 & 23 & 19 & 22 & 23 & 30 & 23 & 27 & 27 & 25 \\
\hline Am-4\% & 18 & 13 & 10 & 10 & 10 & 15 & 16 & 10 & 15 & 17 & 18 & 14 & 17 & 16 & 17 \\
\hline Am-5\% & 11 & 7 & 6 & 7 & 7 & 9 & 11 & 7 & 10 & 10 & 12 & 9 & 11 & 11 & 10 \\
\hline Am-6\% & 8 & 4 & 4 & 4 & 4 & 6 & 5 & 3 & 5 & 6 & 7 & 5 & 7 & 7 & \\
\hline Am-7\% & 5 & 2 & 3 & 2 & 2 & 3 & 3 & 2 & 2 & 4 & 4 & 3 & 4 & 5 & \\
\hline Am-8\% & 4 & 2 & 2 & 2 & 2 & 1 & 1 & 0 & 1 & 1 & 3 & 2 & 2 & 3 & \\
\hline Am-9\% & 3 & 2 & 2 & 1 & 1 & 0 & 1 & 0 & 0 & 0 & 2 & 1 & 1 & 2 & \\
\hline Am-10\% & 2 & 2 & 1 & 0 & 0 & 0 & 0 & 0 & 0 & 0 & 1 & 0 & 1 & 1 & \\
\hline
\end{tabular}

\section{E7024}

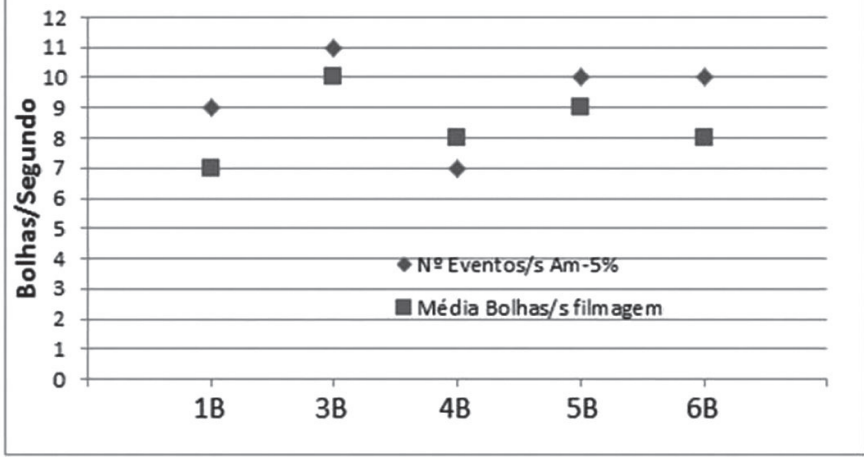

Figura 15 - Comparativo Eventos/s 5\% menores que $\mathrm{A}_{\mathrm{m}}$ e a média bolhas/s registrados com a filmagem - Eletrodo E7024

Com exceção dos corpos de prova $3 \mathrm{~A}$ e $5 \mathrm{~A}$ do eletrodo E6013, nota-se uma grande semelhança entre estes eventos, apresentando diferenças menores que dois eventos em todos os corpos de prova. Tal fato pode sugerir a possibilidade de haver uma relação entre uma diminuição brusca da corrente e o destacamento das bolhas.

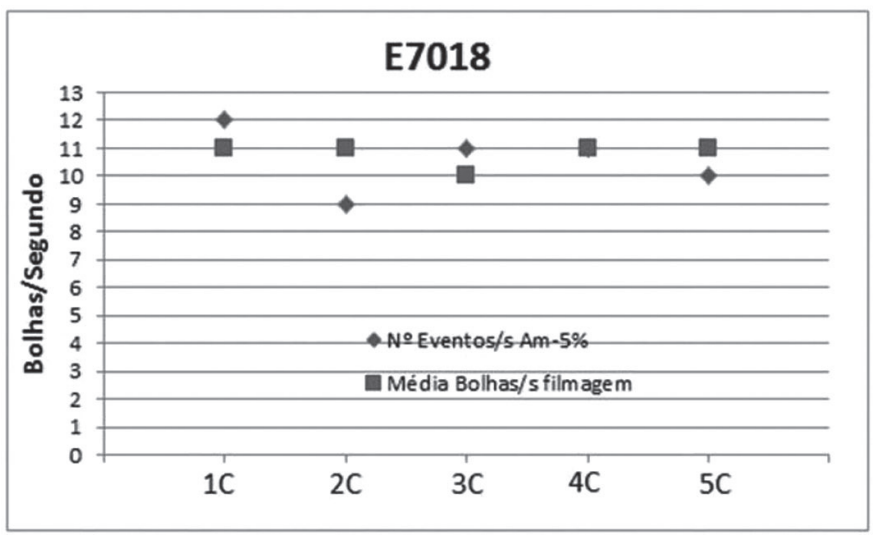

Figura 16 - Comparativo Eventos/s $5 \%$ menores que $\mathrm{A}_{\mathrm{m}}$ e a média bolhas/s registrados com a filmagem - Eletrodo E7018
Outra observação feita através da análise dos sinais de corrente são que as quedas bruscas de corrente (abaixo de 5\% da corrente média) acontecem repentinamente. Não se tem uma diminuição contínua da corrente até esta atingir os valores mínimos, mas sim quedas momentâneas seguidas da retomada dos valores próximos aos anteriormente registrados. Na Tabela 6 são apresentados alguns exemplos destas constatações em momentos aleatórios para corpos de provas distintos dos três tipos de eletrodos. Estas diminuições bruscas estão destacadas em vermelho.

Observa-se também que embora os valores de corrente apresentem estas quedas bruscas repentinas, redução significativa em um ponto e retomada a valores próximos dos anteriores na sequência, não se consegue estabelecer um mesmo padrão no comportamento da tensão durante estes eventos. Em alguns casos a tensão aumenta durante a queda de corrente e em outros casos a tensão diminui. Além disto, as variações de tensão observadas nestes momentos não são significativas quando se toma por base as variações observadas ao longo de todo o processo, notando-se variações maiores que $6 \mathrm{~V}$.

Na Figura 17 é mostrado o oscilograma de tensão x corrente do segundo 5 a 6 do corpo de prova $1 \mathrm{~A}$ onde pode ser vista os momentos onde ocorre a queda brusca da corrente abaixo de $5 \%$ da corrente média.

Uma hipótese para explicar e justificar os eventos descritos acima pode estar relacionada à proteção gasosa do arco e a ionização dos gases presentes na bolha.

Segundo Tsai e Masubuchi [3] e Pope, Medeiros e Liu [4], o arco elétrico está sempre protegido pela bolha durante a soldagem subaquática devido a sua intensidade provocar a vaporização imediata da água circundante.

Villani, Modenesi e Bracarense [9] afirmam que a coluna de plasma compreende praticamente todo o volume do arco, sendo constituída por partículas neutras (moléculas e átomos), íons e elétrons livres. Para a formação do plasma, o gás do arco deve ser aquecido a temperaturas elevadas, para como resultado da agitação térmica ocorrerem choques entre os seus constituintes 
Tabela 6 - Exemplo de queda de corrente para os três tipos de eletrodo

E6013

\begin{tabular}{|c|c|c|}
\hline Tensão (V) & Corrente(A) & Tempo (ms) \\
\hline 34,936 & 160,607 & 6860 \\
\hline 34,967 & 160,588 & 6861 \\
\hline 35,483 & 160,552 & 6862 \\
\hline 35,231 & 161,030 & 6863 \\
\hline 35,852 & 160,073 & 6864 \\
\hline 33,795 & 160,736 & 6865 \\
\hline 36,142 & 161,416 & 6866 \\
\hline 37,456 & 160,680 & 6867 \\
\hline 37,529 & 160,791 & 6868 \\
\hline 37,453 & 160,791 & 6869 \\
\hline 33,467 & 160,680 & 6870 \\
\hline 29,047 & 138,139 & 6871 \\
\hline 31,794 & 163,109 & 6872 \\
\hline 30,298 & 160,736 & 6873 \\
\hline 33,501 & 160,883 & 6874 \\
\hline 35,480 & 160,680 & 6875 \\
\hline 36.840 & 160,662 & 6876 \\
\hline 36,824 & 160,662 & 6877 \\
\hline 36,758 & 160,147 & 6878 \\
\hline 37,467 & 160,809 & 6879 \\
\hline
\end{tabular}

E7024

\begin{tabular}{|c|c|c|}
\hline Tensão (V) & Corrente(A) & Tempo (ms) \\
\hline 32,000 & 160,110 & 440 \\
\hline 29,633 & 160,036 & 441 \\
\hline 29,439 & 160,239 & 442 \\
\hline 31,032 & 159,889 & 443 \\
\hline 31,702 & 159,834 & 444 \\
\hline 32,836 & 160,294 & 445 \\
\hline 32,387 & 161,140 & 446 \\
\hline 31,831 & 159,907 & 447 \\
\hline 31,651 & 159,981 & 448 \\
\hline 31,254 & 159,926 & 449 \\
\hline 31,479 & 159,815 & 450 \\
\hline 30,521 & 159,907 & 451 \\
\hline 30,464 & 160,018 & 452 \\
\hline 30,008 & 149,695 & 453 \\
\hline 31,065 & 150,999 & 454 \\
\hline 30,644 & 159,742 & 455 \\
\hline 30,318 & 160,073 & 456 \\
\hline 30,131 & 160,607 & 457 \\
\hline 30,681 & 159,889 & 458 \\
\hline 30,671 & 160,147 & 459 \\
\hline
\end{tabular}

E7018

\begin{tabular}{|c|c|c|}
\hline Tensão (V) & Corrente(A) & Tempo (ms) \\
\hline 28,092 & 160,975 & 100 \\
\hline 29,269 & 161,913 & 101 \\
\hline 28,596 & 161,858 & 102 \\
\hline 27,935 & 161,895 & 103 \\
\hline 26,611 & 161,950 & 104 \\
\hline 24,793 & 153,136 & 105 \\
\hline 26,509 & 163,017 & 106 \\
\hline 26,551 & 161,895 & 107 \\
\hline 26,791 & 163,698 & 108 \\
\hline 27,149 & 161,876 & 109 \\
\hline 27,878 & 161,821 & 110 \\
\hline 26,789 & 161,876 & 111 \\
\hline 25,489 & 161,895 & 112 \\
\hline 24,861 & 161,932 & 113 \\
\hline 22,636 & 161,012 & 114 \\
\hline 21,490 & 161,821 & 115 \\
\hline 24,282 & 159,135 & 116 \\
\hline 27,161 & 160,662 & 117 \\
\hline 27,880 & 162,171 & 118 \\
\hline 27,078 & 161,803 & 119 \\
\hline
\end{tabular}

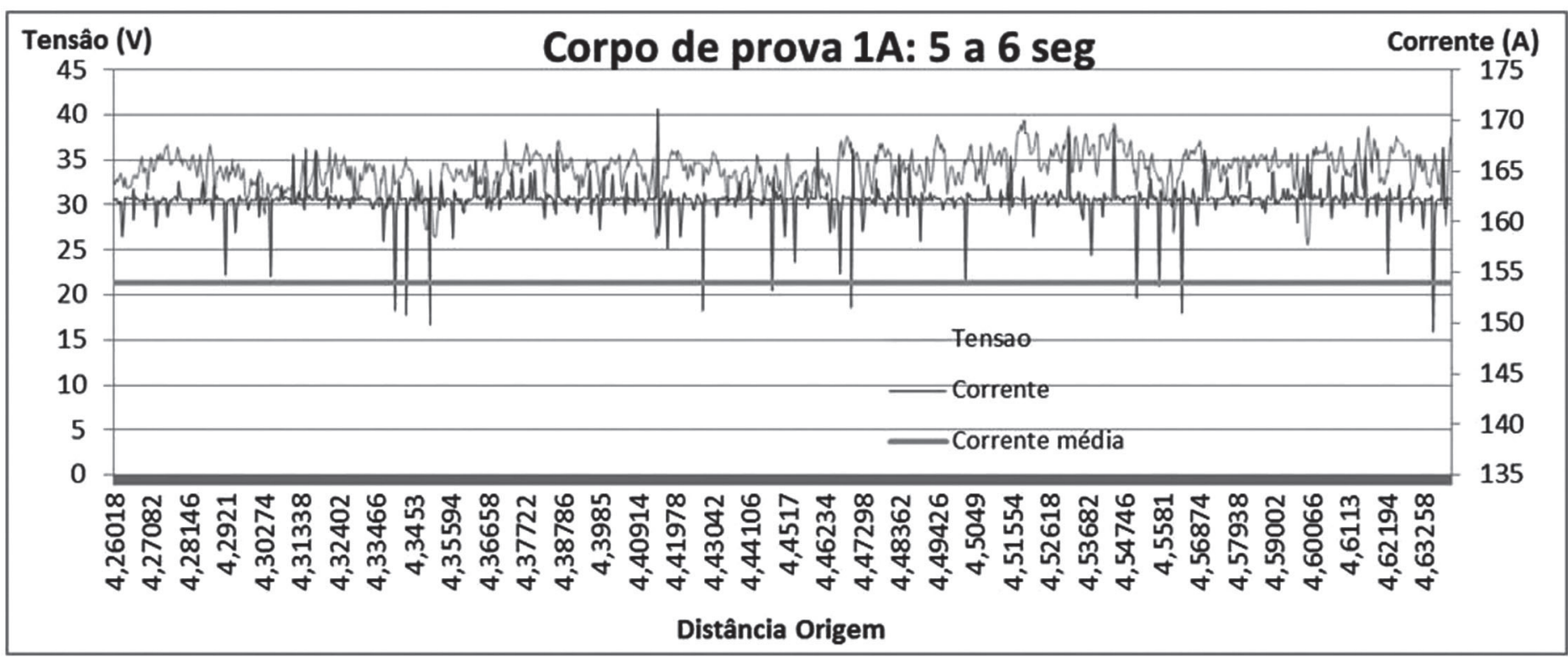

Figura 17 - Oscilograma tensão x corrente do corpo de prova $1 \mathrm{~A}$ - 5 a 6 segundos do processo de soldagem

e a sua ionização. Desta forma, a manutenção contínua do arco elétrico fica condicionada a existência da bolha e da ionização dos gases nela presentes. Então, após o colapso de uma bolha, mesmo com o crescimento imediato de uma nova bolha, poderia haver uma extinção momentânea do arco elétrico que levaria a essa queda brusca e puntual da corrente.
Em outra abordagem, não necessariamente haveria uma extinção do arco elétrico, mas um aumento significativo da resistência elétrica devido à necessidade de haver uma nova ionização dos gases e dissociação da água, o que também levaria a uma queda brusca da corrente.

Segundo Alivov apud Tsai e Masubuchi [1], a presença de 
hidrogênio na região do arco aumenta a resistência elétrica. Desta forma, outra hipótese para a correlação das quedas abruptas de corrente com destacamento das bolhas estaria relacionado a este fato. Com o contínuo aumento da concentração de hidrogênio na bolha, aumenta-se gradualmente também a resistência elétrica na região do arco elétrico. Esta concentração pode chegar a um limite tal que causa uma diminuição significativa da corrente do arco, causando uma perturbação no mesmo e consequentemente levando a um destacamento da bolha.

\section{Conclusões}

Observou-se que o fenômeno de destacamento das bolhas acontece de forma aleatória, com variações nas taxas por segundo em que ocorrem. Notou-se também que estes fenômenos de destacamento podem estar relacionados com o tipo de eletrodo utilizado, pois se encontrou valores diferentes nas taxas de destacamento, bolhas/segundo, para cada um dos três tipos de eletrodo utilizado.

Ao se comparar os resultados das taxas de bolhas/segundo do modelo matemático desenvolvido por Tsai e Masubuchi [1] com as encontradas neste trabalho observou-se uma considerável diferença entre os mesmos. Enquanto estes autores calcularam uma taxa de 15 bolhas/segundo para o eletrodo E6013, foi verificada neste trabalho uma taxa média de 10 bolhas/segundo para o mesmo eletrodo, através da contagem das bolhas na filmagem em alta velocidade. Também divergentes, porém mais próximas, foram as taxas de bolhas/segundo encontradas através da análise da filmagem em alta velocidade no estudo daqueles autores com os encontrados neste trabalho. Enquanto neste trabalho obteve-se uma taxa média de 10 bolhas/segundo para o eletrodo E6013, 8 bolhas/segundo para o E7024 e 11 bolhas/ segundo para o E7018, Tsai e Masubuchi [1] encontraram uma taxa de 13 bolhas/segundo para os eletrodos E6013 e E7014.

Através da observação do comportamento dos sinais de corrente com a frequência de destacamento de bolhas pôde-se notar uma grande semelhança entre a taxa destas e o número de eventos em que a corrente atingiu valores abaixo de $5 \%$ da corrente média em cada cordão. Desta forma, o destacamento das bolhas pode estar diretamente relacionado com variações bruscas de corrente durante o processo de soldagem subaquática. Uma hipótese que justifica esta observação é o aumento repentino da resistência elétrica na região do arco após o destacamento de uma bolha. Após o destacamento da bolha deve haver uma nova ionização dos gases circundantes ao arco elétrico. Com o aumento instantâneo dessa resistência há também uma repentina queda no valor da corrente.

\section{Agradecimentos}

Os autores agradecem ao LRSS (Laboratório de Robótica, Soldagem e Simulação) da UFMG pela oportunidade de desenvolver este trabalho, além de fornecer insumos e materiais necessários para o mesmo.

\section{Referências Bibliográficas}

[1] TSAI, C. L. MASUBUCHI, K. Interpretive Report on Underwater Weldng. Welding Research Council Bulletin, 224, February, 37 pg, 1977.

[2] PESSOA, E. C. P., Estudo da variação da porosidade ao longo do cordão em soldas subaquáticas molhadas. Universidade Federal de Minas Gerais. Brasil, Tese, 2007.

[3] TSAI, C. L. MASUBUCHI, K. Mechanisms of rapid cooling and their design considerations in underwater welding. Offshore Technology Conference. Houston- TX USA. 1979.

[4] POPE, A.M., MEDEIROS, R. C. de, LIU, S. Solidification of Underwater wet Welds. OMAE, Materials Engineering, pp 517-521, 1995.

[5] FILHO, J.C.P., MELLO, R.T., MEDEIROS, R.C., PARANHOS, R. Histórico recente da soldagem subaquática. Infosolda. Disponível em: <www.infosolda.com.br/new_site/ getFile.php?t=d \&i=96>. Acesso em 8 set. 2011, 16:20:13.

[6] TEICHMANN, E. W. Contribuição ao desenvolvimento da soldagem molhada com arames tubulares. Universidade Federal de Santa Catarina. Brasil, Tese, 2000.

[7] ANDRADE, G. D., DIAS, W.C. RIBEIRO, L.F., BRACARENSE, A.Q., PESSOA, E.C.P., LIU,S. Efeito do teor de carbono do metal de base e da alma do eletrodo revestido sobre a porosidade em soldas molhadas. Soldagem \& Inspeção, vol.15, no2, São Paulo, 2010.

[8] BRACARENSE, A. Q., PESSOA, E. C., SANTOS, V.R. DOS, MONTEIRO, M. J, RIZZO, F. C., PACIONIK, S., REPPOLD, R., DOMINGUES, J.R., VIEIRA, L. A. Estudo comparativo de eletrodos comerciais para soldagem subaquática molhada. Soldagem \& Inspeção, vol.15, no 4, São Paulo, 2010

[9] VILLANI, P.M., MODENESI,P.J., BRACARENSE, A.Q. Soldagem, fundamentos e tecnologia. $2^{\mathrm{a}}$ ed. Belo Horizonte: Editora UFMG 2007. 362p 